\title{
Etnografías e historias de despojo: una introducción
}

\author{
Julio Arias Vanegas \\ The Graduate Center, The City University of New York (CUNY) \\ Alhena Caicedo Fernández \\ Departamento de Antropología, Universidad de los Andes \\ Editores invitados
}

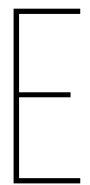

ste volumen de la RCA, "Antropologías del despojo en Colombia II", reúne artículos de investigación que reflejan una variedad de aproximaciones al despojo como un concepto o un problema central en el país, además de un caso sobre Honduras. En Colombia, el despojo, particularmente de tierras, se volvió un tema recurrente durante la última década, pero requiere mayor estudio y debate. A partir de enfoques etnográficos e históricos en diversas geografías del país, los trabajos examinan distintas formas y mecanismos de despojo, sus efectos cotidianos y muchas veces silenciosos, y las luchas en torno a estos. Al igual que en los artículos del anterior dosier, "Antropologías del despojo en Colombia I" ( $R C A$ 52-2), en varios de los que aquí se incluyen se discuten el uso y la transformación social de conceptos como despojo o posesión, así como las posibilidades y limitaciones de la categoría de despojo. En su conjunto, los textos ponen en evidencia la necesidad de no reducir el despojo a un asunto de tierras, al número de hectáreas o a eventos fijos en el tiempo, e ir más allá de explicaciones macro y unidireccionales.

Además de resaltar las principales contribuciones de los artículos de este dosier, en esta introducción discutimos algunos elementos de la categoría de despojo y planteamos asuntos que quedan abiertos para trabajar. Pero antes, no sobra reiterar que es imposible e innecesario aislar el trabajo investigativo y académico sobre despojo de la reciente coyuntura del país, como lo señalamos desde el volumen anterior. La convergencia entre la movilización social, el proceso con los paramilitares, las negociaciones con las FARC y el diseño de programas institucionales estatales, entre otros, ha situado la noción de despojo, y en particular el 
despojo de tierras y territorios, en el centro de diversas agendas políticas (CNRR 2009; Ley 1448 del 2011; Meertens 2016; Ojeda 2016). Este contexto nos obliga a revisar el uso del despojo como herramienta analítica y a considerar los efectos e implicaciones políticas de la investigación al respecto. Sin duda es necesario pensar con mayor detenimiento en las múltiples relaciones y tensiones entre la discusión académica, la movilización social, la legislación y la política pública.

\section{Los artículos: enfoques y contribuciones}

Las contribuciones del presente dosier son varias: iluminan otros conceptos desde el trabajo etnográfico y no solo el de despojo (Morris), abordan la memoria y las narrativas para comprender procesos y efectos diferenciados asociados con el despojo (Calle, León), enfatizan los mecanismos cotidianos y silenciosos de este fenómeno (Camacho), examinan la relación entre el despojo y las configuraciones regionales (Caicedo), y analizan las articulaciones entre despojo y producción de diferencias y desigualdades, ya sean racializadas, de clase o de género (Caicedo, Calle, León).

Abrimos el dosier con el artículo de Meghan Morris sobre una región que ha sido considerada emblemática del despojo asociado al conflicto armado reciente y del diseño de los programas de restitución de tierras en el país: Urabá. Esto la convierte en un lugar único para examinar la complejidad de las luchas por la tierra y las limitaciones del concepto de despojo. Basada en un cuidadoso análisis de las nociones y las historias de vida de múltiples sujetos, Morris muestra que la atención exclusiva en el despojo no captura una diversidad de formas de acceso y tenencia, ni los múltiples significados que la tierra adquiere en ámbitos rurales y urbanos. En la búsqueda por entender las disputas por la tierra, tanto en el acto de quitarla como de adquirirla, la autora resalta la posesión, la ocupación y la invasión, como categorías significativas no solo en el contexto legal, sino que implican prácticas y relaciones particulares con la tierra.

Una contribución importante de Morris es el énfasis en la posesión y en el continuo entre despojo y posesión, que marca la experiencia de los sujetos a lo largo de su vida. Mostrar las dos caras de la moneda, la posesión y el despojo, tiene implicaciones políticas significativas, ya que la comprensión de la lucha por la tierra, las subjetividades políticas o la búsqueda de la equidad no se deberían reducir a una cuestión de víctimas o victimarios. Además, el tipo de análisis aquí propuesto será útil para quienes trabajan en regiones donde las tensiones entre 
la delimitación de baldíos y la posesión se han incrementado, o donde la "buena fe" es objeto de disputas.

La relación entre despojo, privilegio y desigualdad es otra discusión conceptual y política crucial que propone Alhena Caicedo Fernández a partir de un acercamiento a la vida de los pobladores negros de un municipio del norte del Cauca. Allí, la autora analiza la relación entre el modelo de desarrollo regional desplegado en el alto Cauca desde inicios del siglo XX y el despojo de la población local marcada racialmente. Despojo y privilegio son parte de una misma lógica de poder que configura y a la vez es constituida por formas de desigualdad persistentes. Al examinar proyectos de "desarrollo" emblemáticos, como la hidroeléctrica de la Salvajina, rastrea las particularidades de los efectos racializados del despojo por la construcción de la represa y sus acumulados históricos, así como los mecanismos de ocultamiento de los privilegios que generan este tipo de intervenciones. La lógica de poder del despojo/privilegio en la configuración histórica del norte del Cauca también se observa en las nuevas economías extractivistas e ilegales del oro y la coca que vienen tomando fuerza en esta zona. Estas economías, a pesar de presentarse como diferentes y contrapuestas al modelo de desarrollo regional basado en la agroindustria de la caña, reproducen muchas de las formas de despojo y privilegio que han configurado históricamente esta región. Así mismo, generan mecanismos similares de ocultamiento de estas lógicas del poder mediante sus articulaciones con la legalidad y la ilegalidad.

Una contribución de este trabajo es el análisis de larga duración que hace énfasis en los efectos de las desigualdades generadas, entre otras, por la racialización, la etnicidad y la clase, y su persistencia en la configuración histórica de una región. Este tipo de propuestas lleva los análisis del despojo hacia la indagación sobre los agentes que lo promueven, bajo distintas estrategias, a las formas de privilegio que de allí se desprenden y a los beneficiarios del despojo de otros en contextos concretos.

El artículo de Laura Calle explora otra relación entre historia y despojo: la construcción de la memoria, en este caso de los sikuanis, sobre el abandono forzado de su territorio. Al examinar dos momentos cruciales, La Violencia de los años cincuenta y la adjudicación de reservas indígenas en las décadas de 1960 y 1970 en el municipio de Puerto Gaitán, Meta, la autora trasciende el debate reciente sobre las políticas de tierras y el multiculturalismo. A partir de un análisis de los proyectos de colonización, las adjudicaciones de baldíos y la delimitación de resguardos en diversos relatos sikuanis, Calle explora una larga historia de despojo del territorio indígena como parte del control territorial del Estado. Los relatos revelan el papel de conceptualizaciones de raza y civilización en los 
procesos de despojo, de encerramiento de recursos y de legitimación de la violencia estatal. La memoria de esta violencia, relacionada con la expansión de la ganadería extensiva, fundamenta la construcción de la territorialidad sikuani y los reclamos actuales por la recuperación del territorio. El artículo llena así un vacío en la investigación sobre los sikuanis y sobre la Altillanura, una región cuya configuración histórica ha sido poco investigada y que actualmente es centro de atención de grandes proyectos agroindustriales alentados por el Estado. En su análisis, Calle también propicia reflexiones pertinentes en torno a la definición y adjudicación de baldíos, como una acción que puede ser a la vez un ejercicio de violencia estatal y una forma de distribución social de la tierra.

Juana Camacho nos lleva a otra región importante en la historia agraria y de colonización del país, La Mojana, en el Caribe colombiano, para mostrar otros mecanismos y objetos de despojo vinculados con la contaminación por el uso de agroquímicos tóxicos en los cultivos de arroz comercial. Este caso muestra de manera novedosa una particular forma de despojo invisible, silenciosa y cotidiana, resultado de prácticas agrícolas que han sido justificadas y promovidas en nombre del bienestar y el mejoramiento de la producción. El uso naturalizado de agroquímicos en el arroz vulnera sigilosamente los cuerpos, la salud y la alimentación de la gente, mientras que la acción de los tóxicos afecta bienes comunes como el agua, lo que menoscaba los sistemas agroalimentarios al tiempo que refuerza otras formas de despojo. Un aporte central de este caso es señalar que el despojo puede ser un efecto de prácticas consentidas por quienes son sus víctimas y no solo resultado de una acción coercitiva. Otro punto a señalar del trabajo son las particularidades temporales y espaciales de estas formas sutiles y constantes de despojo, que fluyen y se acomodan en lugares e intersticios donde es difícil rastrear sus trazas inmediatas. No obstante, el acumulado tóxico en los cuerpos y ambientes eventualmente se expresa en la salud, los modos de vida y en el daño ecosistémico a largo plazo.

Cerramos el dosier con el artículo de Andrés León sobre el Bajo Aguán en Honduras, donde analiza la relación entre despojo, trabajo y género. Después de haber sido un escenario central para la reforma agraria hondureña en los años sesenta, en las últimas décadas el Bajo Aguán ha vivido un sangriento proceso de contrarreforma agraria paralelo a la expansión del monocultivo de palma africana. A partir de discusiones sobre despojo, acumulación primitiva y clase, León examina la historia de este cultivo, pero introduce una óptica de género poco empleada en este tipo de análisis. La historia de vida de una pareja, su trayectoria familiar y laboral, le sirve al autor para indagar por la experiencia diferenciada de las mujeres en el proceso de acumulación y, en particular, su lucha contra la 
venta de las tierras de una cooperativa. Con base en este examen, León ofrece dos aportes conceptuales significativos: primero, que este tipo de acumulación no solo despoja la tierra sino "el trabajo viviente”, y por tanto la producción de trabajadores es un correlato del despojo. Segundo, que estos procesos no solo resultan en una mayor dependencia de las unidades domésticas del mercado, sino en una pérdida de la autonomía política femenina.

Sin duda, este artículo será relevante para aquellos interesados en la expansión del monocultivo de palma en el país y estimulará etnografías y comparaciones (Hart 2016) que vinculen a Centroamérica, el Sudeste Asiático y Colombia, a fin de entender los distintos modelos y paisajes palmeros, así como las relaciones laborales y políticas que producen. Aunque el modelo de las cooperativas de palma en Honduras difiere de las que se han establecido mayoritariamente en Colombia, el trabajo de León nos hace reflexionar sobre los efectos despojadores de iniciativas como las alianzas productivas (véase la recién aprobada Ley Zidres $^{1}$ ) y las implicaciones de género de programas específicos de desarrollo rural y de formalización o restitución de tierras (Meertens 2016).

\section{Categorías y cartografías}

Una constatación importante emanada de estos dosieres sobre despojo es la variedad de definiciones y aproximaciones conceptuales que suscita esta categoría, y que refleja las orientaciones y marcos teóricos disímiles de los autores. Mientras varios de ellos están influenciados por enfoques marxistas, algunos dialogan con la reciente literatura sobre acaparamiento de tierras y otros privilegian concepciones y efectos más culturales. Sin pretender agotar el debate o cerrar la categoría, a continuación señalamos y planteamos algunas discusiones conceptuales que consideramos centrales para abordar el despojo.

En general, vemos que los artículos parten de una concepción común del despojo como la privación o pérdida violenta de la posesión, goce y aprovechamiento de un recurso o un bien —entendidos de forma amplia-. Los presupuestos de esta definición ameritan ser desmenuzados. Un elemento fundamental es,

1 Esta ley, sancionada por la Presidencia de Colombia en enero del 2016, permitirá que empresas agroindustriales privadas exploten los baldíos de la Nación en ciertas regiones del país consideradas aisladas y despobladas. Aunque la ley plantea incentivar las asociaciones entre empresarios y campesinos, se diferencia significativamente de la legislación anterior de baldíos que priorizaba su adjudicación a campesinos y colonos sin tierra. 
sin duda, el del carácter violento. Al respecto es importante resituar el despojo como parte de "la así llamada" (en el sentido original de Marx) acumulación primitiva u originaria, en la que la violencia no solo es constitutiva sino permanente en la formación y la expansión del capitalismo (De Angelis 2000; Federici 2004; Hart 2016; Marx 1975; Perelman 2000; y León en el presente dosier)². Sin embargo, habría que insistir en que la violencia que entraña el despojo puede no ser solo el producto de una acción coercitiva que se ejerce sobre unos sujetos. De hecho, puede pasar inadvertida y funcionar de manera sutil con el consentimiento de sus propias víctimas. Aunque asuma estas modalidades consensuadas, la expresión violenta del despojo resulta de la supresión, corte, pérdida o privación de algo que es significativo para la reproducción de la vida de quien lo sufre 3 .

Asimismo, el despojo es central en la configuración de relaciones de explotación y en la producción de desigualdades y privilegios, que es justamente uno de los énfasis de los dosieres. Si entendemos la desigualdad como una distribución diferencial de insumos estratégicos, es posible decir que no es una sola. Hay múltiples formas de desigualdad que coexisten de acuerdo con los contextos sociales e históricos y pueden estar o no legitimadas y naturalizadas. En ese marco, la persistencia histórica de ciertas desigualdades genera condiciones que favorecen el despojo (véase también RaizAL 2015). De allí que sea necesario examinar de qué formas concretas las desigualdades propician o facilitan procesos de despojo - y no solo al contrario-, y cómo estos procesos producen y reproducen privilegios de distinto tipo. La concreción etnográfica e histórica al respecto es importante puesto que, desde las narrativas que sustentan el capitalismo, los privilegios y el despojo parecen un asunto del pasado, mientras que estas mismas narrativas naturalizan la igualdad de oportunidades, el emprendimiento o, más recientemente, la innovación.

2 Esta insistencia es necesaria en el contexto colombiano donde, desde ciertas perspectivas institucionales y normativas, se considera que el despojo fue sobre todo parte de un momento de la acción de los grupos armados ilegales, particularmente paramilitares, y resultado del abandono o la ausencia estatal. En estas visiones se presume que el momento del despojo se está superando con las negociaciones de paz y gracias a la presencia del Estado en todo el territorio. Sin embargo, la ausencia del Estado ha sido un concepto central en los mismos procesos de formación del Estado en Colombia (González 2014; Ramírez 2015; Serje 2012), y en este sentido justificaría procesos de despojo, como puede ocurrir con la Ley Zidres.

En contraste con algunas visiones más institucionales, entendemos que el despojo es un proceso complejo no reducible al daño físico o material por la privación de la propiedad legal o del acceso a un recurso, sino que tiene implicaciones psicológicas y morales al fracturar relaciones y vínculos afectivos y simbólicos con lugares y paisajes. Esta condición refuerza su carácter cualitativo, entendiendo que no puede limitarse, en su concepción o en su impacto, a efectos cuantificables. 
Por su parte, la mayoría de los análisis sobre el despojo suelen mostrar aquello que sucede del lado de los despojados. Pocos son los trabajos que identifican y rastrean el lado de los despojadores, sus mecanismos de acción y prácticas de poder y privilegio. En varios casos, se señalan la acción del Estado, la ley o el modelo de desarrollo como las instancias que propician formas de despojo. Ese tipo de encuadres, sin embargo, tienden a invisibilizar el hecho de que, detrás de eso que llamamos Estado, de la ley o del modelo de desarrollo, operan sujetos concretos en momentos y lugares específicos, que no solo se benefician de las formas de despojo de otros, sino que adquieren desde allí privilegios puntuales. Ahora bien, el llamado a preguntarse por la agencia del despojo no debe desconocer el hecho de que la relación entre despojo y privilegio no es directa, ni inmediata, sino que debe ser rastreada contextualmente en cada caso.

Cuando se discute la relación entre despojo, violencia y desigualdad, la tierra aparece como un objeto recurrente tanto en los procesos históricos como en la literatura al respecto. Un ejemplo fundacional es el relato de Marx (1975) sobre el encerramiento y desaparición de las tierras comunales en Inglaterra. No obstante, y como ha sido claro desde el primer dosier, el despojo y sus efectos no deben limitarse a la tierra como un asunto de propiedad formal, ni al robo o abandono de predios. Además, los bienes o recursos despojados son diversos: el agua, la comida, los bosques, los animales y las semillas. Aunque podríamos ampliar la lista, queremos insistir en otro punto: la tierra no debe ser vista como un objeto dado y aislado de otros. Además, la idea de que la tierra únicamente es un recurso o un bien, a diferencia del territorio que sí tiene implicaciones culturales y políticas, no solo es insuficiente sino que da cuenta de visiones peculiares y limitadas por historias específicas (Li 2014) ${ }^{4}$. Las relaciones materiales y simbólicas que las personas tejen con aquello que llamamos tierra, y que para algunos es una entidad con poder en sí misma, son diversas. Así que señalar que la tierra no es lo único que se despoja aumenta el riesgo de reducir y simplificar los procesos y efectos mismos del despojo.

Por esta vía, el ejemplo de la tierra, entre otros, debería llevarnos a plantear una mirada crítica a las nociones de recursos y bienes (Jaramillo 2013; Li 2014; Richardson y Weszkalnys 2014), y a considerar etnográfica e históricamente preguntas como: ¿quiénes y de qué manera definen algo como un bien o un

4 En Colombia, el concepto de territorio tomó una gran fuerza para resaltar dimensiones culturales e identitarias, y de esta manera ha sido fundamental tanto en el ejercicio estatal como en las luchas de movimientos sociales y étnicos. Sin embargo, esto ha implicado la reproducción problemática de la idea de que la tierra no tiene estos sentidos culturales y, al mismo tiempo, la desconexión entre las luchas contra la explotación y la desigualdad de las luchas identitaria (véase Yie 2016, con respecto a los territorios agroalimentarios). 
recurso? ¿Cómo y bajo qué principios circulan o no ciertos bienes? ¿Cuándo y cómo algo o alguien es definido, delimitado y materializado como un bien a ser poseído, despojado o explotado? ¿De qué manera se adquieren o legitiman los derechos de propiedad o de explotación sobre un bien o un recurso?

Estas consideraciones nos remiten a una cuestión más general: si bien el despojo habla de una relación y de su ruptura violenta, esta relación no siempre es considerada en términos económicos o legales. Tampoco se define en todos los casos como una relación entre un sujeto individual poseedor y un objeto material que se posee. En este sentido, los análisis sobre el despojo se beneficiarían mucho de aproximaciones antropológicas a la propiedad (Gluckman 1943; Humphrey y Verdery 2004; Jaramillo 2013), que son muy útiles para entender que la propiedad se construye no solamente desde la ley y los títulos formales, sino desde diversos vínculos y prácticas materiales y simbólicas (Demian 2007; Hetherington 2011; Malinowski 1935). Estas aproximaciones permiten resaltar el carácter histórico y culturalmente situado de las nociones de propiedad privada o colectiva, de la comunidad y el propietario individual, así como mostrar que cualquiera de ellas es fruto de la naturalización de violencias y exclusiones (Gluckman 1965; Hetherington 2011; Verdery 2003). Una mirada crítica y más amplia de la propiedad, y por esta vía del despojo, nos permitiría mostrar cómo las relaciones de propiedad, variadas y disímiles, implican distintas concepciones de los elementos y términos mismos de la relación, por ejemplo, de la gente y de la tierra. También el análisis de las relaciones de propiedad nos llevaría a examinar etnográficamente cómo se adjudica valor a algo, no solamente en términos monetarios (Graeber 2002; Verdery 2003). En este marco general, algunas de las preguntas etnográficas relevantes sobre el despojo no solo se orientan a establecer quién es o fue el titular de algo, sino quiénes y cómo pueden usar ese algo, y quiénes se beneficiarían del valor que le ha sido asignado o que ha producido.

Un último elemento que queremos señalar sobre el concepto de despojo es su relación con lo justo, que por supuesto no se reduce al ámbito legal. Como lo detalla Yie (2016), el despojo puede ser visto no solo como un acto violento sino injusto o ilegítimo, es decir, se usa para denunciar. Por ello mismo, el concepto, como muchos en las ciencias sociales que no solo sirven para explicar sino también para cuestionar e intervenir las realidades sociales (Arias y Caicedo 2016; Yie 2016), resulta complicado y a veces incómodo para algunos académicos. Además, es claro que lo justo y lo legítimo son construcciones arbitrarias; por ejemplo, lo que funcionarios estatales definen como una expropiación legal puede ser visto por otros como un acto de despojo. Sin abogar por un relativismo que puede resultar improductivo, queremos enfatizar que lo justo y la justicia son 
construcciones que emergen de apuestas y disputas sociales y que tienen efectos concretos y materiales. Así, insistimos en que el análisis del despojo implica enfrentar las supuestas posiciones de neutralidad de los científicos e investigadores sociales, para examinar, por ejemplo, cómo ciertas leyes específicas se convierten en mecanismos y fuentes de legitimidad de procesos de despojo (Bosa 2016, Calle en este volumen).

Con estas consideraciones conceptuales en mente, queremos enfatizar, además del valor de la etnografía, la necesidad de potenciar las perspectivas históricas y regionales. Aunque estas son marginales o están ausentes en algunas aproximaciones antropológicas, las contribuciones de los dos dosieres demuestran su relevancia. Al abordar otros momentos históricos e iluminar otras historias regionales, varios de los artículos reflejan la importancia de ir más allá de la coyuntura reciente para entenderla mejor. A su vez, todos evidencian las ventajas y posibilidades de una perspectiva procesual, y en ocasiones de más larga duración, alimentadas por las historias de vida y la construcción de la memoria, que no son tan comunes en las miradas más macro del despojo. Si el trabajo de campo y la etnografía hacen posible aproximarse a la cotidianidad y la localidad, que suelen pasar inadvertidas en otros ámbitos, la perspectiva histórica devela otros ritmos y temporalidades que puede asumir el despojo. Los análisis de larga duración permiten trascender los efectos inmediatos del despojo, rastrear mecanismos de despojo en distintas escalas y visibilizar encadenamientos históricos. Las estrategias metodológicas que ofrecen contrastes de este orden relativizan aquello que se percibe como fijo e inmutable.

En ese marco, otra constatación es la relevancia teórica y metodológica que adquieren las regiones -y sus procesos de configuración histórica-, como productos privilegiados para observar las formas de concreción del despojo y sus efectos. Los artículos de estos dosieres no estudian las regiones como meros contextos o escalas, sino como configuraciones políticas y sociales moldeadas por los procesos de colonización, las economías productivas y extractivas y las políticas estatales, entre otras 5 . Este tipo de encuadres complejiza ciertas miradas de los estudios regionales donde se privilegian perspectivas geográficas y económicas que desconocen la densidad de las disputas de poder que también configuran lo

5 Los artículos publicados ilustran una particular geografía del conocimiento sobre el despojo: la mayoría se enfoca en contextos rurales del Caribe, y en menor medida de Cauca y Nariño, y dejan de lado una buena parte del país. Lo anterior no solo revela una concentración en lugares comunes de trabajo de los antropólogos y el énfasis de vieja data en ciertas luchas campesinas y relaciones y conflictos por la propiedad, sino la historia reciente de los programas de restitución de tierras. Un gran reto es abrir el trabajo a otras regiones y geografías, que desde ya se perfilan a raíz los nuevos procesos de restitución de tierras en el sur del país, asociados con las negociones de paz con las insurgencias. 
regional. Sin embargo, hay que indagar aún más cómo los mismos procesos de despojo producen regiones específicas material y simbólicamente, y no solo las destruyen como entidades dadas. Como lo resalta Ojeda (2016), esto implica potenciar perspectivas espaciales en las que el espacio sea visto desde una compleja dialéctica entre producción y destrucción (véanse también Hart 2016; Lefebvre 1992).

Así como señalamos la relevancia de la región, consideramos que es preciso relativizar el nación-centrismo, o el nacionalismo metodológico (véase Chernilo 2006), tan arraigados en la investigación en el país, y trascender los análisis de escala nacional. El diálogo y la comparación con otros lugares e historias son necesarios, más aún si consideramos el despojo como constitutivo del capitalismo, el acaparamiento de tierras como un fenómeno creciente y acelerado en el sur global (Edelman, Oya y Borras 2015), y el encerramiento de diversos bienes públicos y comunes como un hecho global propio del establecimiento y las transformaciones del neoliberalismo (Harvey 2004) ${ }^{6}$. Al respecto es importante recordar la propuesta de Hart (2016) acerca de las etnografías y los métodos de comparación relacional, que no buscan mostrar simplemente una variedad de casos como expresiones de procesos globales, sino dar cuenta de significados, memorias e historias concretas de despojo para identificar procesos de conexión y desconexión, así como contradicciones y posibles alianzas políticas.

\section{Algunos retos futuros del concepto de despojo}

En los últimos tiempos, el mundo enfrenta fenómenos como el extractivismo, el acaparamiento de tierras, los monopolios financieros, la agudización de discursos y gobiernos xenófobos y racistas, entre otros, que ponen en evidencia contradicciones del capitalismo global. Reconocer el despojo como patrón de poder del capitalismo requiere a su vez comprender los mecanismos de producción y reproducción histórica de este sistema y sus múltiples determinaciones, articulaciones y contradicciones. En ese sentido, cobra una especial relevancia la investigación situada en configuraciones de poder que enlazan despojo, raza, etnicidad, género y clase en relación con la economía política global. A pesar de la exacerbación

6 Por ello decidimos publicar y traducir artículos y reseñas sobre otros lugares distintos a Colombia. 
del multiculturalismo en la investigación antropológica más reciente, la clase social demuestra ser importante en muchos de estos análisis. Esta resurge como una categoría necesaria para comprender la producción de diferenciaciones y desigualdades ligadas al sistema económico global, que funcionan como un producto social situado con connotaciones materiales, espaciales y morales.

Las discusiones anteriores se conectan con otro aspecto fundamental que pocas veces se considera al aproximarse al despojo: el trabajo y las relaciones laborales. En términos amplios, el despojo implica la interrupción de ciertas relaciones de propiedad y la generación de otras, que ocurren paralelas a la producción de nuevos sujetos trabajadores y la destrucción de otras formas de trabajo. Al respecto, León (en este volumen) plantea que lo que se acumula mediante el despojo es el trabajo viviente y que en este proceso es fundamental la producción de sujetos disponibles y versados en ciertos trabajos. Asimismo, en los procesos de acaparamiento y despojo de tierra, Tania Li (2011) hace un llamado a preguntarse qué pasa con la gente que fue despojada de sus tierras, si se convierten en fuerza de trabajo en sus mismas tierras y en qué condiciones, o si son expulsadas porque no son valoradas como mano de obra o porque la tierra tiene otro valor. Igualmente, de varios de los artículos que presentamos se desprende la importancia de estudiar cómo la producción de trabajadores está mediada por la construcción de diferencias raciales o de género, y cómo la legitimación y naturalización de ciertos procesos de despojo presuponen que ciertos trabajadores sean vistos como más adecuados que otros para ciertas tierras o ambientes, lo cual nos lleva de nuevo a preguntarnos de qué manera son concebidas ciertas tierras.

Como lo hemos señalado, además de ser una categoría analítica clave para la comprensión de la configuración social del poder en Colombia, el despojo también es un concepto usado políticamente por distintos actores sociales que recurren a esta noción como herramienta discursiva en sus disputas por la hegemonía. Desde el volumen anterior, advertimos sobre los disímiles usos sociales de la noción de despojo en los últimos años en Colombia. Al intentar contextualizar dichos usos, consideramos que la relevancia académica y política de esta categoría no puede desconocer el reciente momento de "posacuerdos". Es decir, si durante décadas el despojo fue un concepto central en la legitimación discursiva de la lucha armada, es importante indagar por el lugar de esta categoría en la actual transición política producto de la negociación e implementación de los acuerdos de paz con las insurgencias.

Actualmente el despojo es un concepto presente en la formalidad institucional y la ley, pero cada vez tiene más eco en reivindicaciones y denuncias de movimientos sociales frente a las fuentes de conflicto social y ambiental, 
particularmente aquellas relacionadas con el extractivismo y los modelos de desarrollo dominantes. En ese sentido, son significativas las reelaboraciones semánticas por parte de las organizaciones y los movimientos sociales que retoman el despojo como un concepto-herramienta en la disputa por la hegemonía. Así también resulta especialmente relevante la visibilización de conflictos sociales que habían permanecido ocultos bajo la retórica del conflicto armado.

Por esta vía, la relación entre despojo y acción política es un campo de exploración sugestivo para comprender cierta dimensión de la producción de subjetividades políticas, tanto históricas como contemporáneas. Es común resaltar el vínculo entre el despojo y la pérdida de la autonomía y la acción política. Sin embargo, limitarse a ese vínculo implica darle una connotación ontológica al despojo que privaría a los sujetos de cualquier posibilidad de acción. El ser “despojado” no equivale al fin de la agencia y la movilización política. Creer que sí implicaría reproducir la idea de que el propietario individual ${ }^{7}$ es el sujeto político privilegiado. Por el contrario, como forma de poder, el despojo también produce distintas subjetividades (Butler 2013) y, con ellas, distintas modalidades de agencia. En cualquier caso, es necesaria la indagación etnográfica sobre la manera en que el despojo o ser despojado generan formas determinadas de marginación, así como de movilización y participación política. Lo que debe quedar claro es que tanto las categorías y las posiciones de despojadores y despojados, poseedores y desposeídos, como de víctimas y victimarios, no pueden agotar la discusión ni la acción política (véase Morris en el presente volumen).

En ese mismo marco, otro campo de indagación se abre más allá del lugar común que liga al despojo con la idea de bienes. Para ciertos movimientos sociales existe una relación entre despojo y derechos que vale la pena rastrear. ¿Qué implicaciones tendría el asumir que hay un despojo del derecho a la igualdad, cuando aparece una política de derechos diferenciales para ciertas poblaciones, como lo han planteado ciertos movimientos campesinos frente a las políticas diferenciales étnicas? Esta perspectiva sobre el despojo sin duda está conectada con aquella que analiza el carácter moral del concepto y su potencial para designar visiones de lo justo, que activan la acción política. Ahora bien, teniendo en cuenta la riqueza que se derivaría de las múltiples exploraciones del concepto, llamamos la atención sobre la importancia de trabajar en torno a casos concretos y sobre la prudencia necesaria para saber hasta dónde se puede estirar el concepto sin que se convierta en un cascarón vacío, donde cabría cualquier cosa.

Por último, no podemos dejar de reconocer que, en estos dos volúmenes dedicados al despojo en Colombia, siete de nueve artículos son contribuciones de 
mujeres que abordan esta problemática desde diferentes perspectivas ${ }^{7}$. Esto no fue algo que hubiéramos determinado previamente o que consideráramos en la evaluación y selección de los artículos. Pero es un hecho significativo teniendo en cuenta que se trata de campos y debates que funcionan como bisagra entre la academia y la política y que, al igual que la cuestión agraria y de la tierra en Colombia, han sido usualmente dominados por hombres. Además, no es un dato menor en un contexto en el que las universidades, las instituciones burocráticas y el trabajo de campo siguen operando bajo lógicas y valores asociados a lo masculino y donde el trabajo de las mujeres tiende a ser inferiorizado, y por eso muchas veces apropiado y explotado sin reconocimiento.

El dosier central está seguido por la sección “Cuestiones de método”, donde Martina Avanza y Gilles Laferté proponen una reflexión crítica en torno a un concepto central en las ciencias sociales y la antropología: la identidad. A partir de su insatisfacción con lo que consideran los límites políticos y analíticos del concepto y sus usos, los autores retoman cuatro trabajos de sociólogos e historiadores anglosajones y franceses, quienes emplean otras categorías sociales, como identificación, imagen social y pertenencia, que sirven como alternativas para la investigación y el análisis más complejo de fenómenos sociales. Las discusiones planteadas por Avanza y Laferté son relevantes de cara a las políticas identitarias modernas, la institucionalización del multiculturalismo y la agudización de la intolerancia, el racismo y la xenofobia que emergen a raíz de las interdependencias y tensiones económicas y político-institucionales que acompañan la globalización neoliberal.

Un segundo dosier del volumen, “Arqueología, bioantropología y formación de comunidades”, presenta contribuciones de colegas en el campo de la arqueología en Colombia. En primera instancia, Miguel Delgado nos ofrece un amplio panorama del poblamiento temprano del territorio colombiano a partir de investigaciones arqueológicas y bioantropológicas que proponen diversas hipótesis sobre este proceso y su relación con la diversidad biocultural de la población. Por su parte, Helen Hope Henderson examina la formación de comunidades cacicales en sociedades muiscas con base en el análisis comparativo de asentamientos regionales andinos, del cambio social y del ejercicio del poder. El artículo de Alberto Sarcina presenta los resultados de una investigación dirigida a identificar y delimitar la ubicación de Santa María de la Antigua del Darién y de su puerto

7 El artículo de Gillian Hart y dos de las reseñas también fueron escritos por mujeres. 
marítimo. Los hallazgos llenan vacíos de conocimiento en torno de esta primera ciudad española en las Américas, y abren nuevas líneas de trabajo sobre los asentamientos previos y aquellos con los cuales mantuvo relaciones sociales y económicas durante la Conquista.

\section{Agradecimientos}

Queremos agradecer a quienes hicieron posibles estos dos dosieres sobre el despojo. Ante todo, al equipo de la RCA: a Carlos Andrés Meza, por acoger el tema como anterior editor de la revista, y a Juana Camacho, actual editora, y María Eva Mangieri por la guía, las lecturas juiciosas, la constante presión y el meticuloso e incansable trabajo. La labor del equipo editorial de las revistas muchas veces es invisibilizada y por ello es más fácilmente apropiada y despojada por todo el aparataje de las instituciones, universidades y bases de datos. En este mismo sentido, también es necesario agradecer a los evaluadores quienes, aunque muchas veces no son reconocidos públicamente por las curiosas convenciones académicas, fueron fundamentales para concretar estos dosieres. Mil gracias a los autores de los artículos y reseñas y a las traductoras, por su paciencia, disposición y constancia en este largo proceso.

En estos dosieres convergen el trabajo de miembros del ICANH, del Centro de Pensamiento RaizAL, y de colegas que participaron en un simposio en el Congreso Colombiano de Antropología del 2015 y en un taller en la Pontificia Universidad Javeriana en agosto del 2016. A todos les agradecemos inmensamente su apoyo, sus evaluaciones y sus comentarios, muchas veces muy críticos, en especial a Carlos Alberto Benavides, Diana Bocarejo, Carlos del Cairo, Juana Camacho, Alejandro Camargo, Jennifer Devine, Marc Edelman, Paola García, Claudia Leal, Andrés León, Kristina Lyons, Carlos Andrés Meza, Diana Ojeda, Eduardo Restrepo, John Jairo Rincón, Dianne Rocheleau, Esteban Rozo, Marta Saade, Maite Yie, Shawn van Ausdal, Daniel Varela e Irene Vélez. 


\section{Referencias}

Bosa, Bastien. 2016. “¿Despojados por ley? Los efectos del Decreto 68 de 1916 de la Gobernación del Magdalena sobre la población arhuaca”. Revista Colombiana de Antropología 52 (2): 107-138. DOI: https://doi.org/10.22380/2539472X41.

Butler, Judith. 2013. Dispossession: The Performative in the Political: Conversations with Athena Athanasiou. Cambridge, RU: Polity Press.

Chernilo, Daniel. 2006. “Social Theory’s Methodological Nationalism: Myth and Reality”. European Journal of Social Theory 9 (1): 5-22.

Comisión Nacional de Reparación y Reconciliación (CNRR). 2009. El despojo de tierras y territorios. Aproximación conceptual. Bogotá: Área de Memoria Histórica, Comisión Nacional de Reparación y Reconciliación; Iepri.

De Angelis, Massimo. 2000. Marx's Theory of Primitive Accumulation: A Suggested Reinterpretation. Londres: University of East London.

Demian, Melissa. 2007. “'Land doesn't Come from your Mother, She didn’t Make It with Her Hands': Challenging Matriliny in Papua New Guinea”. En Feminist Perspectives on Land Law, editado por Hilary Lim y Anne Bottomley, 155-170. Londres: Routledge-Cavendish.

Edelman, Marc, Carlos Oya y Saturnino M. Borras, Jr. 2015. Global Land Grabs: History, Theory and Method. Londres: Routledge.

Federici, Silvia. 2004. Caliban and the Witch. Nueva York: Autonomedia.

Gluckman, Max. 1943. Essays on Lozi Land and Royal Property. Livingstone, Northern Rhodesia: Rhodes-Livingstone Institute.

—. 1965. The Ideas in Barotse Jurisprudence. New Haven: Yale University Press.

González, Fernán E. 2014. Poder y violencia en Colombia. Bogotá: Odecofi-Cinep.

Graeber, David. 2002. Towards an Anthropological Theory of Value: The False Coin of our Own Dreams. Nueva York: Palgrave.

Hart, Gillian. 2016. "Desnaturalizar el despojo: una etnografía crítica en la era del resurgimiento del imperialismo”. Revista Colombiana de Antropología 52 (2): 139-173. DOI: https:// doi.org/10.22380/2539472X42.

Harvey, David. 2004. El nuevo imperialismo. Madrid: Akal.

Hetherington, Kregg. 2011. Privatizando lo privado en el campo paraguayo: lotes precarios y la materialidad de los derechos. Asunción, Paraguay: Intercontinental Ed.

Humphrey, Caroline y Katherine Verdery. 2004. "Introduction: Raising Questions about Property”. Property in Question Value Transformation in the Global Economy, editado por Caroline Humphrey y Katherine Verdery, 1-25. Oxford: Berg.

Jaramillo, Pablo. 2013. Las servidumbres de la globalización. Viento, créditos de carbono y regímenes de propiedad en La Guajira, Colombia. Buenos Aires: Clacso.

Lefebvre, Henri. 1992. The Production of Space. Malden, MA: Blackwell. 
Ley 1448. 2011. Ley de Víctimas y Restitución de Tierras y decretos reglamentarios. Por la cual se dictan medidas de atención, asistencia y reparación integral a las víctimas del conflicto armado interno y se dictan otras disposiciones. Bogotá, República de Colombia.

Li, Tania. 2011. “Centering Labor in the Land Grab Debate”. Journal of Peasant Studies 38 (2): 281-298.

-. 2014. "What is Land? Assembling a Resource for Global Investment". Transactions of the Institute of British Geographers 39 (4): 589-602.

Malinowski, Bronislaw. (1935) 1965. Coral Gardens and their Magic. Bloomington: Indiana University Press.

Marx, Karl. 1975. El capital: crítica de la economía política. México D. F.: Siglo Veintiuno.

—. 1993. Grundrisse. Londres; Nueva York; Penguin Adult.

Meertens, Donny. 2016. “Entre el despojo y la restitución: reflexiones sobre género, justicia y retorno en la costa caribe colombiana”. Revista Colombiana de Antropología 52 (2): 45-72. DOI: https://doi.org/10.22380/2539472X39

Ojeda, Diana. 2016. "Los paisajes del despojo: propuestas para un análisis desde las reconfiguraciones socioespaciales”. Revista Colombiana de Antropología 52 (2): 19-44. DOI: https:// doi.org/10.22380/2539472X38.

Perelman, Michael. 2000. The Invention of Capitalism: Classical Political Economy and the Secret History of Accumulation. Durham: Duke University Press.

RaizAL-Centro del Pensamiento Latinoamericano. 2015. "Apuntes sobre procesos de despojo/privilegio”. Revista Intervenciones en Estudios Culturales 2: 35-41. https://intervencioneseecc.files.wordpress.com/2016/03/art03_cplr_apuntes-sobre-procesos.pdf.

Ramírez, María Clemencia. 2015. "The Idea of the State in Colombia: An Analysis from the Periphery”. En State, Theory and Andean Politics: New Approaches to the Study of Rule, editado por Christopher Krupa y David Nugent, 35-55. Filadelfia: University of Pennsylvania Press.

Richardson, Tanya y Gisa Weszkalnys. 2014. "Introduction: Resource Materialities”. Anthropological Quarterly 87 (1): 5-30.

Serje, Margarita. 2012. "El mito de la ausencia del Estado: la incorporación económica de las ‘zonas de frontera’ en Colombia”. Cahiers des Amériques Latines 71 (3): 95-118.

Verdery, Katherine. 2003. The Vanishing Hectare: Property and Value in Postsocialist Transylvania. Itaca: Cornell University Press.

Yie, Maite. 2016. "Narrando (desde) el despojo. Mediaciones morales y conceptuales de la noción de despojo en las luchas de los sectores populares rurales de los Andes nariñenses”. Revista Colombiana de Antropología 52 (2): 73-106. DOI: https://doi.org/10.22380/2539472X40. 